\title{
Estado, desenvolvimento e direitos humanos na fronteira amazônica: a violência do encontro entre o indígena e o não indígena no Território Federal do Guaporé
}

\author{
Vinícius Valentin Raduan Miguel \\ Universidade Federal de Rondônia,PortoVelho, Brasil \\ Email: viniciusmiguel@unir.br
}

\section{Adnilson de Almeida Silva}

Universidade Federal de Rondônia, PortoVelho, Brasil

Email: Email: adnilsonn@gmail.com

\section{Dorisvalder Dias Nunes}

Universidade Federal do Pará, Brasil.

Email: dorisvalder@pq.cnpq.br

\section{Nilson César Fraga}

Universidade Estadual de Londrina (UEL), Brasil.

Email:ncfraga@gmail.com

\begin{abstract}
Resumo: O presente artigo busca refletir sobre as relações de "encontro de sociedades" entre indígenas e não indígenas na porção sul da Amazônia Ocidental brasileira, bem como discutir os projetos de desenvolvimento e as políticas de direitos humanos aplicados na região na década de 1950. Neste contexto, a discussão de fronteira, ambiente e sociedade é promissora, por não se tratar apenas das relações de fronteira, como consideração científica, em razão de outras possibilidades que perpassam a materialidade do Estado-Nação, visto que se inscrevem em questões econômicas, políticas e sociais interligadas a territorialidades com funções, processos e significados de apreensões territoriais e espaciais distintos. Numa região de fronteira econômica, os recursos naturais são considerados fartos é inegável a busca incessante para sua exploração por meio de mecanismos que sempre ou quase sempre resultam em "encontros de sociedade”, ou seja, entre os migrantes e as populações locais no caso, as indígenas - sendo que tais "encontros de sociedades" são realizados por enfrentamentos, que em seu contexto é configurado em processo de resistência em contraponto a novas dinâmicas territoriais.
\end{abstract} rondônia.

Palavras-chave: Amazônia, direitos humanos, encontro de sociedades, 


\title{
Estado, desarrollo y derechos humanos en la frontera amazónica: la violencia del encuentro entre lo indígena y lo no indígena en el Territorio Federal do Guaporé
}

Resumen: Esto artículo refleja en las relaciones de "encuentro de las sociedades” entre pueblos originarios y no indígenas en la porción sur de la Amazonia occidental brasileña, además de discutir los proyectos de desarrollo y derechos humanos las políticas aplicadas en la región en la década de 1950. En este contexto, la discusión de la frontera, medio ambiente y sociedad es prometedor, no sólo por tratarse de las relaciones de frontera, como consideración científica, a causa de otras posibilidades que pertenecen a la materialidad del Estado-Nación, dado que se sitúan en temas económicos, políticos y sociales conectados a territorialidades con funciones, procesos y significados de aprensiones territoriales y espacios diferenciados. En una región de frontera económica, los recursos naturales son considerados abundantes y, por lo tanto, es innegable la búsqueda incesante de su explotación por medio de mecanismos que siempre o casi siempre resultan en "encuentros de sociedad", es decir, entre los migrantes y las poblaciones locales - en este caso, las indígenas - siendo que tales "encuentros de sociedades" son realizados por los enfrentamientos, que en su contexto se configura en el proceso de resistencia en contrapunto a las nuevas dinámicas territoriales. rondônia.

Palabras Claves: Amazonia, derechos humanos, encuentro de sociedades,

\section{State, development and human rights in the amazon frontier: the violence of the encounter between the indigenous and the non-indigenous in the Federal Territory of Guaporé}

\begin{abstract}
This reflects on relations of "meeting of societies" between indigenous and non-indigenous in the southern portion of the Western Amazon brazilian, discussing the projects of development and human rights policies applied in the region in the decade of 1950. In this context, the discussion of border, environment and society is promising, not just border relations, as scientific consideration, on account of other possibilities that pertain to the materiality of the Nation-State since enrolling in economic, political and social issues connected to territorialities with functions, processes and meanings of territorial seizures and distinct space. In a region of economic border, natural resources are considered sick it is undeniable the incessant search for their exploitation by means of mechanisms that always or almost always result in "meetings of society", i.e. between migrants and local populations - in this case, the Indians-being that such "meetings of societies" are performed by clashes, which in its context is configured in the process of resistance in counterpoint to new territorial dynamics.
\end{abstract}

Keywords: Amazon, human rights, meeting of societies, rondônia.

$* * *$

\section{Considerações iniciais}

O trabalho discorre sobre o encontro do indígena (povo originário) com o não indígena (indivíduos e instituições estatais) no Território Federal 
do Guaporé, hoje Estado de Rondônia, situado na Amazônia Legal. O período em apreço, a década de 1950, foi um momento de alteração da estrutura produtiva (o qual privilegia o setor industrial sobre o agrícola) no plano nacional. Com a expansão da fronteira, graças aos maciços investimentos e programas estatais para levar o que se propugnava enquanto "desenvolvimento", a nova população e as dinâmicas populacionais (que se deslocavam em direção ao Norte do país) aceleraram o encontro com o indígena. Na região em análise, a decadência da forma extrativista da borracha cedeu espaço para a exploração da cassiterita - que assumiu posição de destaque, o que configura para alguns autores, como o "ciclo da mineração” em Rondônia, a partir da metade da década de 1950 e que prossegue hegemônica por mais duas décadas. No entanto, a mineração seguia os mesmos moldes estruturais de exploração (monocultura), a qual estava atrelada às necessidades econômicas exógenas (Rabello, 2004; Miguel, 2008; Santos, 2011).

A população local (indígenas e comunidades tradicionais) era reiteradamente ilustrada como um problema para o avanço das relações de produção hegemônicas. Se a região era representada como "atrasada"/ "subdesenvolvida", suas populações tradicionais não recebiam quaisquer considerações, logo se concretizavam e integravam, por parte do Estado brasileiro um processo de apagamento/ausência ou invisibilidade, de forma intencional. Assim, eram - essas populações - apresentadas como inexistentes ou, senão, como entraves para as elites econômicas e seus interesses. Nessa seara, afirma Cemin que:

“[...] Ao longo das sucessivas expansões imperialistas a Amazônia e sua população vêm sendo alvo de extermínio, exploração e sujeição. As populações de índios e ribeirinhos vêem sendo espoliadas sob a justificativa do desenvolvimento para isso são equiparadas a monstruosidades e relegadas à esfera da infra-humanidade. Entretanto, os planos de desenvolvimento vêem se constituindo historicamente como "dádivas-veneno" a essa mesma população, pois ao desorganizar seus modos de vida, retirando-lhes a territorialidade, alterando a lógica de sua organização social, baseada no parentesco e na reciprocidade, condena essa população à condição de miséria nas periferias urbanas e rurais [...]” (2009: 1).

Especificamente no período em observação (década de 1950), a região amazônica se via sob a influência de novos programas de integração/ desenvolvimento nacionais, dentro do contexto geopolítico caracterizado como "Marcha para o Oeste” brasileiro e de ocupação da Amazônia. Tal fato de ocupação/integração e desenvolvimento está diretamente relacionado ao declínio do II Ciclo da Borracha, sendo que a Constituição de 1946, em seu artigo 199 definia o Plano de Valorização Econômica da Amazônia (PVEA) determinava um montante a ser investido nesta região considerada de "vazio demográfico" em razão da incipiente densidade demográfica. 
Mas foi tão somente sete anos depois, que houve o estabelecimento da Lei nº 1.806/1953, a qual delineava o PVEA e instituía a Superintendência do Plano de Valorização Econômica da Amazônia (SPVEA), o que de direito deu força normativa à Carta Política, como estratégia geopolítica de integração do território brasileiro e ocupação planejada de áreas de fronteira na região.Com isso, impulsionaram-senovas atrações migratórias, em virtude dos investimentos estatais na Amazônia, o que, por sua vez, reforçavam os“encontros de sociedades” (Galvão, 1979), ou seja, entre culturas com valores, sentidos e representações distintas de mundos, no caso indígenaenão indígena.

É importante destacar que na Amazônia, no período compreendido desta análise (décadas de 1940 e 1950), a extração e a produção do látex obtido especialmente da seringueira (Hevea brasiliensis), da sorva (Coumautilis (Mart.) Muell. Arg., Apocynaceae) e do caucho (Castillaulei) atendiam aos interesses do mercado internacional. Em decorrência de fatores externos, como a Segunda Guerra Mundial e o receio de ocupação estrangeira, o Estado brasileiro afirma sua forte influência geopolítica na região e cria em 1943, por meio do Decreto 5812 os territórios federais do Guaporé (modificado para Rondônia em 1956), Rio Branco (mudado para Roraima em 1962) e Amapá, posteriormente transformados nos atuais estados de Rondônia (1981), Roraima e Amapá (1988)em áreas fronteiriças ao sul e ao norte da Amazônia.

Logo, todo o processo produtivo dependia de uma série de estratégias geopolíticas apoiadas e financiadas pelo governo brasileiro como é o caso das instituições criadas para tal finalidade - cujo contexto se reproduziu com a consequente ocupação de imensas áreas espacialmente despovoadas pela sociedade não indígena, mas habitadas pelos indígenas, o que produziu o encontro de sociedades e perdas territoriais de diversas etnias (Almeida Silva, 2012; 2015). Fato esse que ocorreu em praticamente toda a Amazônia.

\section{Trajetórias teóricas e conceituais}

O trabalho interpreta o Estado e suas agências enquanto elemento que sofre as influências da dinâmica histórico-social e espacial. Dessa forma, o controle e uso dos espaços resultam e expressam as lutas e interações sociais (Cemin, 2007; Mendonça, 1998). De modo que todo projeto ou política de intervenção sobre uma região manifesta o embate de agentes político-econômicos.

Os projetos de desenvolvimento de uma região preceituam ser imperativo ocupá-la, pelo fato de construir uma narrativa de "espaços de colonização” (in casu, a Amazônia). Tais espaços são descritos como vazios de povos e desabitados de culturas e, por isso mesmo, “abertos” à exploração do colonizador (Kothari, 2005).O desenvolvimento pode ser descrito como uma forma de terrorismo, como pugnado pelo professor indiano 
ShivVisvanathan (1997) ou de política voltada à morte, conceituadocomo "necropolitics" por Mbembe (2003).

Portanto, apresenta-se como uma forma gradual e lenta de genocídio, com a intenção de suprimir o Outro. Assim, as duas noções ("espaços de colonização" e "desenvolvimento como terrorismo" / "necropolitics") se completam: a região Amazônica foi, por vezes, apresentada como cultural e demograficamente desocupada, carecendo de um preenchimento proveniente de outra localidade. Se tal vácuo existia, era permitido ignorar as populações e conhecimentos amazônicos.Não se tratava de eliminá-los, pois eles não existiam no contexto dado e apresentado pelo Estado brasileiro.

Neste sentido, a compreensão sobre Estado, desenvolvimento e direitos humanos na Amazônia está diretamente interligada ao contexto geográfico e histórico que ocorria à época na região, onde sua relevância é destacada por Almeida Silva ao considerar que:

“[...] A importância sobre a discussão de fronteira, ambiente e sociedade é propícia à medida que se se trata não somente dos aspectos da fronteira, enquanto conceito científico, porque envolve outros desdobramentos que perpassam pela materialidade como Estado-Nação e se insere em questões econômicas, políticas e sociais que dizem respeito a territorialidades com funções, processos e significados de apreensões territoriais e espaciais distintos.

Numa região de fronteira econômica, em que os recursos naturais são considerados abundantes é notório uma busca incessante para sua exploração através de mecanismos que sempre ou quase sempre resultam em "encontros de sociedade", ou seja, entre aqueles que chegam e a população residente. Esses encontros são marcados por enfrentamento, cujo contexto se configura no processo de resistência em oposição à numa nova dinâmica espacial/territorial [...]” (Silva, 2012:8).

Consigne-se que para o recorte sócio-espacial não temos um território qualquer, mas uma região aberta à exploração econômica - que posteriormente é conceituada como "fronteira econômica”, “uma válvula de escape para as tensões sociais e demográficas produzidas pela expansão capitalista nas áreas povoadas” (Becker, 1988: 63), de modo que o Estado transfere a problemática para áreas territoriais mais novas de modo a reproduzir antigas formas de sua atuação verificadas nas antigas áreas.

Atinente a essa questão, não é menor monta frisar que a fronteira é o ponto de açambarcamento do lócus da alteridade e de encontro de modos culturais antagônicos. Dessa dialética da diferença, o efeito é sempre socialmente modificativo, o qual resulta em mudanças e reconfiguração dos modos de produção, sistemas de propriedade e conjuntos simbólicos envolvidos no encontro. Na abordagem Martins expressa que:

“[...] A fronteira, a frente de expansão da sociedade nacional sobre 
territórios ocupados por povos indígenas, é um cenário altamente conflitivo de humanidades que não forjam no seu encontro o homem e o humano idílico da tradição filosófica e das aspirações dos humanistas. A fronteira é, sobretudo, no que se refere aos diferentes grupos dos chamados civilizados que se situam "do lado de cá”, um cenário de intolerância, ambição e morte [...]” (2009: 9).

O autor aprofunda tal discussão que apresenta resultados de estranhamentos de distintas culturas, em regiões de fronteira, ao inferir que se trata de perspectivas de entendimento social, político, ambiental, enfim de vivência e visão de mundo ao situar que:

“O que há de sociologicamente mais relevante para caracterizar e definir a fronteira no Brasil é, justamente, a situação de conflito social. E esse é, certamente, o aspecto mais negligenciado entre os pesquisadores que têm tentado conceituá-la. Na minha interpretação, nesse conflito, a fronteira é essencialmente o lugar da alteridade. É isso o que faz dela uma realidade singular. À primeira vista é olugar do encontro dos que por diferentes razões são diferentes entre si, como os índios de um lado e os ditos civilizados de outro; como os grandes proprietários de terra, de um lado, e os camponeses pobres de outro. Mas o conflito faz com que a fronteira seja essencialmente, aum só tempo, um lugar de descoberta do outro e de desencontro”. (Martins, 2009: 133).

Assim, as Políticas de Desenvolvimento Regional para a Amazônia encarnaram o "mito do indígena como obstáculo" nos processos colonizatórios na Amazônia, e “justificam” o massacre desses povos para a expropriação de seus territórios, o qual substitui-os por outros saberes, estruturas culturais, modos de produzir e regimes de propriedade (Ott, 2002; Cemin, 2007; Almeida Silva, 2012; 2015). O caso guaporense/rondoniense não ficou a desejar, pois plasma no imaginário coletivo que as intervenções estatais de planejamento regional serviriam para a ocupação de um espaço sem gente, e promoveram a defesa territorial e a integração nacional (Rabello, 2004; Miguel, 2008).

\section{Percurso metodológico}

Enquanto coleta de dados, utilizamos a Análise de Conteúdo, visto que buscamos por palavras a partir das fontes escolhidas, como passamos a explicar (Bryman, 2008). Foram apreciadas fontes hemerográficas, no caso, o Jornal Alto Madeira, cujo acervo encontra-se disponível no Centro de Documentação Histórica da Secretaria de Estado de Cultura (CDH/SECEL RO) e atualmente denominada de Superintendência Estadual de Cultura, Esporte e Lazer, em Porto Velho, capital rondoniense. Definimos enquanto palavras-chave as expressões: “aborígine”, “índio”, “indígena”, “nativo”, "silvícola”, originários e suas variantes, como plurais.Procedeu-se à coleta dessas matérias jornalísticas, com a elaboração de um relatório para 
arquivamento dos já referidos dados (Bryman, 2008). Neste sentido, propositalmente utilizamos as expressões índios e indígenas. A primeira refere-se ao tratamento dado naquele período, por parte da sociedade nacional envolvente e cuja insistência denominativa permanece nos dias atuais - a qual etimologicamente tem o sentido, nos dias atuais, de servidão, colonialismo e preconceito. A segunda corresponde à referência como esses povos étnicos buscam-se definir, como protagonismo de atuação política, e como procuram difundir suas culturas e aferir a cidadania no contexto da sociedade brasileira.

Ademais, foram aferidas legislações em vigor à época em estudo sobre a temática, ao determos sobre a forma e a narrativa jurídica do indígena. Especificamente, apreciamos a Constituição de 1946, o Decreto 8.072/ 1910, o qual em "Crêa o Serviço de Protecção aos Índios e Localização de Trabalhadores Nacionaes e approva o respectivo regulamento" e o Decreto 5.484/1928 que "Regula a situação dos indios nascidos no território nacional” (sic) que tratam sobre a questão indígena.

Analisamos esses dados, foram decompostos com os significados do encontro entre o indígena e o não indígena na legislação identificada e nas matérias jornalísticas da época.Atentamos para, na tentativa de identificar os discursos de alguns agentes/setores, não incidir na reprodução da narrativa oficial (Mendonça, 1998).Tal equívoco, no caso em observação, levaria à perpetuação de concepções estereotipadasdo Outro/indígena.

\section{A Constituição como desconstituição do Indígena}

O primeiro texto legal, em ordem cronológica, em vigor à época, era o Decreto 8.072/1910. Tal formulação jurídicafoi muito clara ao definir o papel do Serviço de Proteção do Índio (SPI). Os preceitos da norma determinavam uma aproximação “branda” para despertar a atenção dos indígenas para a alteração da construção de habitações, bem como atraí-los para a "civilização", de modo a modificar suas organizações sociais, políticas e culturais por meio da introdução da agropecuária, e interligar as aldeias com os centros de consumo.

O Decreto 5.484/1928 mantém a mesma disposição legal ao reiterar a distinção entre índios e civilizados e instituicomo critério de aquisição de capacidade (em termos jurídicos), a "incorporação" com a sociedade civilizada - a hegemônica.

Neste sentido, os seguintes excertos do Decreto 8.072/1910 deixam a questão mais clara ao expor a ideia de domesticação e submissão dos povos indígenas e/ou originários no território brasileiro:

“[...] Art. 20, "11”, envidar esforços por melhorar suas condições materiaes de vida, despertando-Ihes a attenção para os meios de modificar a construcção de suas habitações e ensinando-lhes 
livremente as artes, officios e os generos de producçãoagricola e industrial para os quaes revelarem aptidões; [... ] "14", fornecer aos indios instrumentos de musica que lhes sejam apropriados, ferramentas, instrumentos de lavoura, machinas para beneficiar os productos de suas culturas, os animaesdomesticos que lhes forem uteis e quaesquer recursos que lhes forem necessarios; introduzir em territoriosindigenas a industriapecuaria, quando as condições locaes o permittirem; (grifos nossos.)” (Decreto 8-072/1910).

Assim, se tem que pela disposição legal que as populações originárias são consideradas como incapazes e por isso compete ao poder público (Estado nacional) em inseri-los na “civilização”, conforme demonstra o art. 11, "Paragraphounico. O governo, sempre que julgar necessario, fará construir casas para residencia dos indios e estradas de rodagem para ligação dos aldeiamentos aos centros de consumo" (grifos nossos). Finalmente, o art. 14 versava que:

“[...] A directoria, por intermedio dos inspectores, procurará, por meios brandos, attrahir os indios que viverem em estado nomade e prestará aos que se mantiverem em promiscuidade com civilizados a mesma assistencia que lhe cabe dispensar aos mais índios” (grifos nossos).

No período contextual do período (décadas de 1940-1950) analisado o instrumento legal trazia embutido um projeto pedagógico, que imputava à educação o papel de introduzir novas formas de socialização do indígena. Nele, o indígena deveria abandonar o estágio nômade/coletor para fixar-se, em uma forma societal sedentária e produtora e, se possível, interconectada com os centros de consumo não indígenas. A meta estipulada pelo Decreto era a desarticulação das formas sociais indígenas e sua incorporação à forma capitalista de produção, o que de fato significaria a perda de seus territórios para as frentes de ocupação colonizadora, ou em síntese, transformaria essas populações em agricultores/trabalhadores rurais nos moldes do sistema econômico vigentes da época em questão. Ressalta-se, que na atualidade, os indígenas brasileiros assumem um protagonismo de autonomia, no sentido de participarem como cidadãos da vida do país, inclusive com a definição de estratégias que possibilitam intercambiar o conhecimento externo e a manutenção de seus valores fundamentais, como cultura, educação, espiritualidade, dentre outras questões.

Passamos ao Decreto 5.484/1928. Esse mandamento passou a regular diversas situações do indígena. Em primeiro lugar, estabeleceu uma classificação dos indígenas, de acordo com o grau de integração com a sociedade brasileira. No Decreto fica manifesto que se trata de uma “discriminação” étnica ao definir a situação de inferioridade dos indígenas, que não disporiam de capacidade jurídica para entrar em negócios consigo mesmos ou com os “civilizados”, sendo que os atos praticados por eles seriam considerados atos nulos. Desse modo, colocava-se o indígena em uma posição de subordinação, poisnecessitaria da tutela estatal. 
Uma segunda parte do Decreto dispôs sobre as formas de registros de nascimentos, casamentos e óbitos. Mas merece destaque os artigos 23 a 32, que trouxeram disposições de caráter penal, e delineia os "crimes cometidos contra índios" e "praticados por índios”. Numa leitura mais aprofundada deste Decreto sobre os atos nulos é possível observar que mais uma vez o indígena é retratado como incapaz, como se vê no seu Art. $5^{\circ}$ "A capacidade, de facto, dos indiossoffrerá as restricçõesprescriptas nesta lei, emquanto não se incorporarem ellesá sociedade civilizada”, bem como o Art. $7^{\circ}$ que considera:

"São nullos os actos praticados entre individuos civilizados e indios das $1^{\mathrm{a}}, 2^{\mathrm{a}}$ ou $3^{\mathrm{a}}$ categorias, salvo quando estes forem representados pelo inspector competente, ou quem fizer as vezes deste".

\section{Quadro 1: Qualificativos atribuídos aos indígenas no Decreto 5.484/1928}

\begin{tabular}{|c|c|}
\hline Texto Legal (do Decreto 5.484/1928) & Qualificativos \\
\hline $\begin{array}{l}\text { Art. } 7^{\circ} \text { São nullos os actos praticados entre individuos civilizados e } \\
\text { indios das } 1^{\mathrm{a}}, 2^{\mathrm{a}} \text { ou } 3^{\mathrm{a}} \text { categorias, salvo quando estes forem } \\
\text { representados pelo inspector competente, ou quem fizer as vezes } \\
\text { deste. }\end{array}$ & $\begin{array}{l}\text { Não-Índios: Indivíduos } \\
\text { civilizados } \\
\text { Índios: sem qualificação }\end{array}$ \\
\hline $\begin{array}{l}\text { Art.23. Os crimes de qualquer natureza, commettidos por } \\
\text { civilizadoscontraindios, considerar-se-hão sempre como praticados } \\
\text { por superiorcontra inferior, e, como taes, terão suas penas } \\
\text { aggravadas pela circumstancia do art. } 59, \S 9^{\circ} \text {, in fine, do Codigo } \\
\text { Penal vigente, além das demais em que porventura incorram os } \\
\text { autores. }\end{array}$ & $\begin{array}{l}\text { Não-Índios: } \quad \text { Civilizados, } \\
\text { Superior } \\
\text { Índios: Inferior }\end{array}$ \\
\hline $\begin{array}{l}\text { Art.27. Todo aquelle que, abusando da boa fé, ingenuidade ou } \\
\text { atrazo mental do indio, sujeital-o á exhibição ou espectaculos, } \\
\text { deante de terceiros, com o fim de tirar disto lucro ou proveito, será } \\
\text { punido de accôrdo com os arts. } 180,181 \text {, ou } 182 \text { do Codigo Penal. } \\
\text { (Dos crimes contra a liberdade pessoal, segundo as circumstancias). }\end{array}$ & $\begin{array}{l}\text { Índios: ingenuidade ou atraso } \\
\text { mental }\end{array}$ \\
\hline $\begin{array}{l}\text { Art.28. São equiparados aos menores de que trata o art. } 30 \text { do } \\
\text { Codigo Penalos indiosnomades, os arranchados ou aldeiados e os } \\
\text { que tenham menos de cinco annos de estabelecidamente em } \\
\text { povoação indigena. }\end{array}$ & $\begin{array}{l}\text { Índios: equiparados à situação } \\
\text { de menoridade }\end{array}$ \\
\hline
\end{tabular}

Fonte: Adaptado do Decreto 5.484/1928.

Tal decreto é pródigo em adjetivos que denotam a posição do indígena como "inferior” ou, ainda, "ingênuo" e em situação de "atraso mental”, conforme pode demonstrado no Quadro 1.Assim, o Estado brasileiro, dentro da ideologia da época promove o racismo e a discriminação dos povos originários, cujos desdobramentos ainda se verificam nos dias atuais em decorrência de inúmeros discursos ideológicos que diminuem a importância dos indígenas perante a sociedade nacional envolvente, de modo que resulta em uma série de conflitos, as quais envolvem, sobretudo, a questão territorial. 
Ao que tudo indica o indígena foi construído como um não sujeito, em razão de não possuir capacidade jurídica, com isso não poderia dos atos da vida civil - até mesmo devido aos obstáculos que se coloca do ponto de vista legal, vide o conjunto de leis que não permitem a participação, especialmente, no que se refere à participação política. Sua condição era percebida - pelos instrumentos jurídicos da época e não muito diferente na atualidade - e equivalente como a de menoridade (tal como uma criança) e inferioridade em relação ao não indígena. Mesmo quando a lei buscava assegurar alguma proteção aos indígenas, o fazia com um discurso tomado com o repertório preconceituoso da época, reiterando as descrições de inferioridade do indígena diante da superioridade do não indígena.

Finalmente, a questão indígena também ganhou estatuto constitucional, na Carta Magna de 1946. Todavia, foi mantida a imposição da substituição da forma de vida tradicional indígena pela forma “civilizada”.A única menção que o ordenamento constitucional então em vigor fez aos povos indígenas foi a constante no art. 50, XV, " $\mathrm{r}$ ".

Nesse versículo,foi delimitada como competência exclusiva da União a elaboração de legislação sobre a "incorporação dos silvícolas à comunhão nacional". A inexistência de direitos e garantias constitucionalmente previstos não é despropositada: o não lugar do índio era exatamente o que versículo apontava! O indígena não existia na ordem constitucional - e não deveria existir. O índio deveria ser meramente “incorporado”. Essa condição caracteriza como uma invisibilidade e como tal negava inclusive o direito à própria existência, ao modo de vida, ao território, à cultura, pois deveria negar seus valores ancestrais para que fosse reconhecido como "civilizado" nos moldes da sociedade envolvente.

\section{O Indígena e o Não-Indígena: (des)encontros com o "Desenvolvimento"}

No caso específico do Território Federal do Guaporé - atual Estado de Rondônia - a primeira notícia encontrada nos dados pesquisados alardeava o embate entre os "civilizados" e os indígenas, apresentando-o como ameaça de destruição dos indígenas. Delatava, ainda, os massacres já ocorridos, conflitos dos indígenas com seringueiros e trabalhadores da Estrada de Ferro Madeira Mamoré (EFMM) e a inoperância do SPI (Alto Madeira, 1950a: 1).

Mesmo com seus territórios sendo invadidos, os indígenas eram vistos como algozes e extremamente violentos frente ao processo de ocupação/colonização. Onze dias depois, indígenas atacaram seringueiros em Altamira (hoje Pará), motivando a Associação Comercial local a apresentar seus reclames ao Ministro da Agricultura que encaminhou "telegrama solicitando medidas” (Alto Madeira, 1950b:1). Doze dias depois, no mesmo local, novos fatos eram relatados: seringueiros teriam sido atacados, mas 
escapado vivos de um massacre que teria sido orquestrado pelos índios (Alto Madeira, 1950c:1).

No atual Estado de Rondônia, destacam-se os reclames da sociedade guaporenselocal ao Sr. Gabriel Hermes Filho, então presidente do Banco de Crédito da Borracha (BCA) e atual Banco da Amazônia (BASA).Esse, por sua vez, interpelou o Ministro da Agricultura, João Cleophas e o presidente do SPI, José Maria. De acordo com Gabriel Hermes Filho, os índios “estão perturbando o trabalho em toda a região" e asseverou que "o caso que de tão perto merece esforços dos responsáveis pela produção amazônica" (Alto Madeira, 1951: 3). A interrupção da produção do látex, causada por embates com a população indígena, alcançava o status de problema econômico, ao ponto de obter a atenção das instituições bancárias da região.

Os seringalistas não extraíam apenas o látex na Amazônia, mas igualmente o sangue dos indígenas. É o que se vê dos fatos noticiados do ocorrido em áreas do atual município Ouro Pretod'Oeste (Rondônia), onde um massacre cometido por um seringalista foi relatado pelo indigenista Francisco Meireles, então chefe do SPI (O Imparcial, 1952). Assim, a cada reação dos povos indígenas frente à ocupação de seus territórios, a ação dos seringalistas eram a de promover expedições punitivas, as quais resultavam em etnocídios que não poupavam idosos, mulheres ou crianças. A gana do lucro pelos seringalistas era desmensurada e em muitos casos recebiam o apoio do Estado brasileiro.

“Assim, se realiza a reconfiguração territorial, onde áreas ancestrais e tradicionalmente ocupadas pelos indígenas, se transformam em extensos seringais. Essa nova forma de ocupação pelos seringalistas, no entanto, não ocorreu de maneira pacífica e toda vez que os indígenas empreendiam estrategicamente a defesa de seu espaço territorial atacando os seringueiros, os donos dos seringais, promoviam sistemáticas reações, por meio de expedições punitivas às populações indígenas (LEONEL, 1995; VILAÇA, 1996), que invariavelmente resultaram em etnocídios. [...] Em levantamento realizado por Leonel (1995), no decorrer do século XX aproximadamente uma centena de expedições punitivas foram aplicadas aos indígenas, também a que se considerar que com a decadência dos seringais, devido à desvalorização econômica da borracha em nível mundial, entra em cena nos anos 1950 a exploração mineral em Rondônia, que produz choques interculturais, cujos resultados se refletiram diretamente no modo de vida indígena e com repercussões territoriais”. (Almeida Silva, 2012: 8).

Embora sejam ora apresentados como bárbaros agressores, em algumas ocasiões, a imprensa reconhecia que eram os indígenas que estavam tendo suas terras usurpadas por "invasores” (Alto Madeira,1953a:4) e por isso reagiam, até mesmo porque dependiam delas para sobreviverem.

A "pacificação” dos indígenas era um processo inconcluso. Como eles mantinham a condição de incivilizados, ainda preparavam atos de 
vingança contra os não indígenas. Assim, noticiou-se que Francisco Meirelles, então indigenista, alertava para os desdobramentos da chacina de São Felix, onde vinte membros de um povo originário foram "massacrados covardemente" e que, agora, preparavam a retaliação (Alto Madeira, 1953b:4). Os quadros 2 a 4 no Anexo deste trabalho apresentam ainda que resumidamente o panorama existente no período extrativista da seringa, marcado pelo “encontro de sociedades” no Território Federal do Guaporé, cujos desdobramentos são percebidos ainda nos dias atuais, porém com novos atores sócio espaciais.

O cotidiano de violência se espalhava por toda a década: no mesmo período, um indígena foi assassinado por um seringueiro. O motivo foi que o indígena, acompanhado da mulher e um filho, pedira o filho do trabalhador rural para levar consigo para a aldeia. Com a negativa do seringueiro, ofendeuo verbalmente, sendo por isto, morto com um tiro de espingarda. A mulher do indígena e um filho pequeno foram ainda perseguidos pelo seringueiro com um facão, mas conseguiram fugir. O caso chegou ao Poder Judiciário do Território Federal do Guaporé. Não foram encontrados dados sobre o desfecho desta situação; todavia, independente da absolvição ou condenação do seringueiro, o que prevaleceu foi o brutal encontro entre culturas distintas.

Mas a violência simbólicatambém alcança grande patamar. Segundo o relato noticiado na imprensa,os Gavião (autodenominados Ikolen)- povo indígena da região de Ji-Paraná (Rondônia) que habitam a Terra Indígena Lourdes juntamente com os Arara (Karo) na divisa com Mato Grosso devido ao processo colonizador em Rondônia, foram desterritorializados e reivindicavam do Governador Ênio Pinheiro o retorno a seus territórios ancestrais. Para tanto, permaneceram as margens do rio aguardando a passagem do governador para cumprimentá-lo e oferecer-lhe presentes e ao mesmo tempo entendiam que somente essa autoridade poderia ajudálos, o que denotava uma estratégia que não a do confronto, mas da busca por benefícios estatais. No entanto, não foram atendidos (Alto Madeira, 1954a:1) e a situação decorrida mais de cinquenta anos, ainda permanece a mesma.

Com isso, os Gavião (Ikolen) se encontram inseridos no território ancestralmente ocupado pelos Arara (Karo) e tem como resultados conflitos interétnicos, o que confirma em seu contexto evocar o conceito de "violência simbólica” exposto por Bourdieu, o qual em síntese retrata o desconhecimento da dominação exercitada por outrem, como bem afirmaCeminque "o poder se estabelece não só por coação física, mas também por recursos simbólicos, entre eles a matriz discursiva (discurso que dá origem a discursos)"(2009:2). É imperativo afirmar que esses dois povos possuem valores culturais, sociais, espirituais e modos de vida distintos, os quais se entrechocam em virtude de suas particularidades e visões de mundo.

Soma-se a isso, o fato da existência de uma visão antagônica entre não indígenas e indígenas na região, a qual concorre para o estabelecimento 
específico interno de ordenamento social, regras e normas de cada cultura, que resulta em processos de confronto entre grupos historicamente excluídos (indígenas e pequenos agricultores).

Desse modo, verifica-se que para os indígenas o entendimento e visão do mundo estão vinculados à floresta - e supera a objetividade material - sendo que essa integra sua cosmologia, seu modo de vida e permite as interações e percepções que produzem sentidos e significados no espaço para sua cultura e meios para suprir as necessidades de sobrevivência. Em contrapartida, a lógica dos não indígenas consiste no fato de compreender a floresta e o meio ambiente como oportunidade de auferir recursos financeiros, o que resulta numa intrincada e tensa relação, um jogo do poder, onde o interesse dos mais fortes, quase sempre, se sobrepõe aos demais (Bastos, et al, 2009: 7;14).

O agravamento dos conflitos entre os indígenas e os não indígenas (novos migrantes) tornou-se tão significativo no período (décadas de 19401950) que chamou a atenção da imprensa e foi objeto de editorial do Alto Madeira (1954b: 1), o qual descreve em seu título "O Problema do Índio". No editorial, percebe-se a forma de tratamento para o indígenaque é o de ser tragado para a "civilização", onde poderá realizar "obras de patriotismo". Contatar e "civilizar" o indígena são descritos como "dever” e "obrigações morais" do Estado, para assegurar-lhes "melhores oportunidades de trabalho, de bem estar e de educação". A “integração”, ampliando "o raio de ação civilizadora" permitiria "maior proveito nos benefícios da civilização" é a forma proposta de interação entre o Estado e o indígena. De modo límpido, o editorial opina que os indígenas já “civilizados” sejam utilizados na vitrine estatal para a promoção desse modelo de integração, seduzindo os outros indígenas, ainda arredios e não civilizados - considerados na atualidade como autônomos ou em situação de isolamento voluntário:

"Parece-nos que a efetivação de medidas tendentes a criar condições de vida laboriosa, sadia e feliz às aldeia de indios já trazidas à civilização, poderá concorrer fortemente pelo exemplo e estimulo e que as tribos, mais arredias se aproximem do progresso civilizante e sejam defendidas contra a doença, a perseguição impiedosa, míseras condições dos mais desprotegidos habitantes das selvas” (Alto Madeira, 1954b: 1).

As ideias de defesa nacional e patriotismo também surgem e indicam que a não incorporação (e seguinte desestruturação cultural) do indígena fragilizariam a soberania da região amazônica. Por conta da ameaça à soberania, o SPI começa a ter suas atividades expandidas (Alto Madeira, 1955a).

Os indígenas apareceram nas publicações inclusive como objeto da propaganda para a mudança do nome do Território Federal (de Guaporé para Rondônia) (Alto Madeira, 1955b:1). Em um balanço das atividades de Rondon na região, o deputado federal ÁureoBringel de Melo (PTB-Amazo- 
nas) indica quatro pontos motivadores dessa homenagem: 1. Porque Rondon foi a esperança para muita gente;2. Porque foi ele que trouxe as linhas telegráficas para o Guaporé; 3.Foi ele que catequizou os índios; 4. O Guaporé deve muito a Rondon, porque ele trouxe o desenvolvimento para uma terra tão distante como o Guaporé. O “amansamento” dos índios, assim, colocase no repertório de préstimos do estadista para a região. O projeto foi aprovado por 196 votos a favor, e com apenas 4 votos contrários, todos da bancada da União Democrática Nacional (UDN).

As discussões sobre o local do SPI na Administração Pública se estendeu, e foi apresentado projeto de lei modificativo da estrutura ministerial, o qual manteve, todavia, o Conselho Nacional de Proteção aos Índios e o SPI ao Ministério da Agricultura (Alto Madeira, 1957a: 1). Mas além da reforma administrativa, o SPI, que tinha como chefe da repartição o Senhor Oriculo Castelo Branco, se via esvaziado de recursos financeiros. Fazia-se a programação orçamentária, mas o dinheiro não chegava. De 500 mil cruzeiros planejados para as atividades do órgão, somente $110 \mathrm{mil}$ efetivamente chegaram para ser repartido entre os 5 postos existentes. Mas a matéria sobre o SPI acaba transparecendo suas funções: “[...] levar avante o seu plano de catequese e aproximação do mundo civilizado dos nossos irmãos selvículas”. Ademais, o valor necessário era o dobro do orçado (um milhão de cruzeiros) “cujo mínimo [a aplicação da verba inicialmente orçada] seria a paz nos seringais a garantia de um trabalho sem sobressaltos, o esforço de desbravador das matas recompensados” (Alto Madeira, 1957b: 1).

Desse modo, se o órgão indigenista se não colocava totalmente em favor dos indígenas, mas em apoio ao capital representado pelos seringalistas, os quais usurpavam os territórios indígenas e recebiam a salvaguarda de proteção para expandirem seus negócios nos seringais da região. É preciso destacar que além das investidas sobre os territórios indígenas - com fragrante usurpação dos direitos mais elementares, como a vida - havia outros fatos para aniquilar os povos originários, entre eles, a disseminação de doenças até então desconhecidas pelos indígenas.

\section{Considerações finais}

Notou-se claramente que o papel do Estado em sua política de desenvolvimento e direitos humanos no Território Federal do Guaporé (atual Estado de Rondônia) não foi efetivo, em virtude da noção que se tinha, na época, para com os povos indígenas.

Neste sentido é necessário refletir que o indígena era considerado um ser invisível para a lógica econômica, antes de tudo, era visto como um empecilho para o avanço do “desenvolvimento" que se implantava e almejava para esta porção da Amazônia.

Assim é indispensável constatar que o Estado representado pelo órgão indigenista, o Serviço de Proteção do Índio, tinha dois grandes obje- 
tivos: (i) aproximar o mundo civilizado para o "irmão" indígena, por meio de catequização ou adestramento; e (ii) garantir a paz nos seringais, o que era sinônimo de assegurar a produção da borracha sem interrupção causada por indígenas. Enquanto prevaleceu a lógica da Economia na região, o Outro (o indígena) foi apresentado como ameaça paraa Segurança Nacional ou como estorvo para o avanço dos modos de produção.

O Estado não apenas servia para a coerção física, mas guardou espaço para uma violência simbólica. No caso, o SPI (enquanto agência estatal), setores da imprensa e instrumentos normativos permitiam a difusão de uma cultura hegemônica anti-indígena, e os descreviam como um produto do atraso, cuja superação, se daria por meio da incorporação e da tutela do "civilizado", pois era um dever do Estado e uma obrigação moral (Mendonça, 1998).

O desenvolvimento realizou-se como narrativa hegemônica, alicerçada como referencial o modelo ocidental, cujo projeto conduziu à negação e à destruição do Outro, como asseguram as teses de Visvanathan (1997) e deMbembe (2003). As práticas "vencedoras” cominaram em um desenvolvimento imposto "de cima” para as populações e territórios relacionados, cujos costumes, espacialidades e saberes foram percebidos como vazios e passíveis de supressão pelo modelo capitalista-ocidental (Kothari, 2005). Os povos indígenas e suas territorialidades eram vistos como à deriva, os quais flutuavam sobre as necessidades da "comunhão nacional", consequentemente ignorados e anuladosseus saberes e modos de vida (Sardan, 1995).

A violência discursivadescreve o indígena como não sujeito na gramática do Direito, do Estado, e de seus agentes na tônica do desenvolvimento nesta porção da região amazônica. Dessa forma, o desenvolvimento deu-se como violência para com aspopulações tradicionais e o progresso mostrou-se com a face da barbárie. Com os dados angariados, demonstrou-se que a narrativa tal como constituída do desenvolvimento no caso amazônico foi/é um discurso de eliminação do Outro. O indígena como não sujeito, dentro da lógica do Estado, era retratado sempre privado de fala e cujo substantivo era acompanhado por qualificativos depreciativos.

De certo modo, resguardado às exceções, o tratamento dado atualmente às etnias em Rondônia, e, particularmente, no Vale do Guaporé, não diferem muito do que se verificou no passado. Essa consideração referese ao fato de vários povos indígenas terem perdido seus territórios e não conseguirem recuperá-los, além de constantes ameaças à integridade física, cultural e social, assim, essas populações encontram-se submetidas à lógica urbana, o que inclui a marginalização (dificuldade de acesso educacional, moradia, trabalho, entre outros) 


\section{Bibliografia}

Almeida Silva, A. (2012), “A questão indígena em Rondônia e os projetos de desenvolvimento na Amazônia Ocidental”.Ciência Geográfica, v. XVI, p.8-14, 2012. Disponível em http://www.agbbauru.org.br/publicacoes/revista/anoXVI_1/agb_xvi1_versao_internet/AGB_abr2012_02.pdf. Consultado em 10 fev 2015.

Ídem. (2015). Entre a floresta e o concreto: os impactos socioculturais no povo indígena Jupaú em Rondônia, Paco Editorial, Jundiaí.

Almeida Silva, A\& Ederson Lauri, L. (2010), “Questão indígena na Amazônia, a especificidade de Rondônia: algumas considerações”, emAmaral, José Januário de Oliveira; Leandro, Ederson Lauri (Orgs.). Amazônia e Cenários Indígenas, Pedro \& João Editores, São Carlos,v. 1, p. 45-70.

Amaral, José Januário de Oliveira; Leandro, Ederson Lauri. (Orgs.) (2010),“Amazônia e CenáriosIndígenas”. Pedro \& João Editores, São Carlos.

Alto Madeira (1950a), Ameaçada de perecimento a raça indigena do Brasil. Porto Velho, Jornal Alto Madeira, 19.12.1950. Ano XXXIII. n. 3665, p. 1.

Ídem (1950b), Voltaram os índios a atacar. Porto Velho, Jornal Alto Madeira, 30.12.1950. Ano XXXIII, n. 3671, p. 1.

Ídem. (1950c), Seringueiros Escapam do Massacre dos Índios no Município de Altamira. Porto Velho, Jornal Alto Madeira, 31.12.1950. Ano XXXIII, n. 3672, p. 1.

Ídem. (1951), Medidas deverão ser tomadas. Porto Velho, Jornal Alto Madeira, 03.04.1951. Ano XXXIII, n. 3724, p. 3.

Ídem. (1953a), Conflitos sangrentos entre índios e os invasores de suas terras. Porto Velho, Jornal Alto Madeira, 20.06.1953. Ano XXXVI, n. 4.280, p. 4.

Ídem. (1953b), Quatro mil xavantes preparam a vingança. Porto Velho, Jornal Alto Madeira, 06.11.1953. Ano XXXVI, n. 4398, p. 4.

Ídem. (1954a), Passou por Tabajara o Governador Enio Pinheiro. Porto Velho, Jornal Alto Madeira, 08.01.1954. Ano XXXVI, n. 4450, p. 1.

Ídem. (1954b), O Problema do Índio. Porto Velho, Jornal Alto Madeira, 16.03.1954. Ano XXXVI. n. 4505, p. 1.

Ídem. (1955a), SPI, Serviço de Proteção ao Índio, avança progressivamente. Porto Velho, Jornal Alto Madeira, 18.01.1955. Ano XXXVII, n. 4764. 
Ídem. (1955b), As razões da “Rondônia”. Porto Velho, Jornal Alto Madeira, 04.08.1955. Ano XXXVII, n. 4929, p. 1.

Ídem. (1957a), Superintendente do Serviço de Navegação do Madeira, Joaquim Alves de Morais. Porto Velho, Jornal Alto Madeira, 15.02.1957. Ano XXXIX, n 5380, p. 1.

Ídem. (1957b), Em dificuldades o S.P.I. regional de atender pesados encargos que lhe são afetados. Porto Velho, Jornal Alto Madeira, 14.08.1957. Ano XL, n. 5, p. 1.

Bastos, A.; Almeida Silva, A.; Gomes, F.; Lopes, L. (2009),“Amazônia: territorialidade rondoniense - uma visão geográfica dos seus reflexos para indígenas e não-indígenas”, em I Simpósio Nacional de Geografia Política, Território e Poder (I Geosimpósio), UNICURITIBA/UFPR, Curitiba, v. I, p. 1-16.

Becker, B. (1988), Significância contemporânea da fronteira: uma interpretação geopolítica a partir da Amazônia brasileira, em: AUBERTIN, Catherine. (Org.),Fronteiras. Ed. UnB, Brasília; Orstom, Paris, p. 60-89.

Brandão, C. (2000),“Economia Política e Dimensão Territorial do Desenvolvimento". Anais do V Encontro Nacional de Economia Política. Fortaleza.

Ídem. (2007), “Territórios com classes sociais, conflitos, decisão e poder”, emOrtega, Antônio César; Almeida Filho, Niemeyer (Orgs.) (2007),Desenvolvimento Territorial, Segurança Alimentar e Economia Solidária, Editora Alínea, Campinas.

Brasil. Constituição dos Estados Unidos do Brasil, de 18 de setembro de 1946.

Ídem. Decreto n. 5.484, de 27 de junho de 1928. Regula a situação dos índios nascidos no território nacional. Diário Oficial da União - Seção 1 14/07/1928, p.17125.

Ídem. Decreto n. 8.072, de 20 de junho de 1910. Crêa o Serviço de Proteç̧ão aos Índios e Localização de Trabalhadores Nacionaes e approva o respectivo regulamento. Diário Oficial da União - Seção 1 - 24/06/1910, p. 4788. Republicação em Diário Oficial da União - Seção 1 - 26/06/1910, p.4869.

Ídem. Lei ordinária n. 1.806, de 6 de janeiro de 1953. Dispõe Sobre o Plano de Valorização Economica da Amazonia, Cria a Superintendencia da Sua Execução e da Outras Providencias.

Bryman, A. (2008), "Social Research Methods". $3^{\text {rd }}$ ed. Oxford University Press, Oxford. 
Cemin, A. (2007), “A colonização em Rondônia: imaginário Amazônico e projetos de desenvolvimento - tecnologias do imaginário, dádivas-veneno e violência”, emLabirinto (UNIR), v. VII, n 10 . Disponível em http:// www.cei.unir.br/artigo105.html. Consultado em 10 jan 2015.

Ídem (2009), “Crítica cultural feminista: violência, desenvolvimento e direitos humanos na Amazônia”, emLabirinto (UNIR), v. IX, p. 12.Disponível em http://www.cei.unir.br/artigo124.html. Consultado em 13 nov. 2014.

Galvão, E. (1979), “Encontro de sociedades: índios e brancos no Brasil”, emColeção Estudos Brasileiros, v. 29. Paz e Terra, Rio de Janeiro.

Kothari, U. (2005), “A Radical HistoryofDevelopmentStudies: Individuals, InstitutionsandIdeologies”, Zed Books, London

Leonel, M. (1995), “EtnodicéiaUruéu-au-au: o endocolonialismo e os Índios no Centro de Rondônia”, Edusp/IAMA/FAPESP, São Paulo.

Martins, J. (2009), “Fronteira: a degradação do Outro nos confins do humano”, Contexto, São Paulo.

Mbembe, A. (2003), Necropolitics. PublicCulture, 15(1), p. 11-40. Disponível em http://publicculture.dukejournals.org/content/15/1/ 11.full.pdf+html. Consultado em 10 jan. 2015.

Mendonça, S. (1998), “Estado e Sociedade”, em Mattos, Marcelo Badaró. (Org). História: pensar e fazer. Laboratório Dimensões da História, Rio de Janeiro.

Miguel, V. (2008), Fronteira Ampliada: Relações de Poder em Rondônia (1950-1954). Monografia (Graduação em Ciências Sociais na Universidade Federal de Rondônia), Porto Velho.

O Imparcial. Porto Velho, Jornal O Imparcial, 27.01.1952.

Ott, A. (2002),Dos projetos de desenvolvimento, aos desenvolvimentos dos projetos: o PLANAFLORO em Rondônia. Tese (Doutorado Interdisciplinar em Ciências Humanas na Universidade Federal de Santa Catarina), Florianópolis.

Rabello, A. (2004), Inventando o outro: representações do desenvolvimento e da fronteira amazônica. Tese (Doutorado em Ciências: Desenvolvimento Sócio Ambiental na Universidade Federal do Pará), Belém.

Santos, S. (2011), Desenvolvimento no Território Federal do Guaporé: organização e atuação política da sociedade civil frente os projetos econômicos (Anos 1950). Monografia (Graduação em Ciências Sociais na Universidade Federal de Rondônia). Porto Velho. 
Sardan,J. P. (1995), "Les trois approches en anthropologie du développement“. Disponível em http://matisse.univ-paris1.fr/fr/IMG/pdf/ desardan.pdf. Consultado em 4 fev. de 2015.

Vilaça, A. (1996), Quem somos nós: questões de alteridade no encontro dos Wari com os brancos. Vol. 1. (Tese de doutoramento em Antropologia, Mimeog.). Museu Nacional/UFRJ, Rio de Janeiro

Visvanathan, S. (1997), A carnival for science. Essays on Science, Technology and Development. Oxford University Press, Oxford.

Recibido: 30.03 .15

Aceptado: 16.03.16 


\section{Anexos}

\section{Anexo 1: Editorial “O Problema do Índio”}

\section{O Problema do Índio}

Um dos problemas amazônicos levados ao estudo de Comissão de Planejamento da SPVEA que merece cuidadosa análise e interesse, é o que se refere aos índios. As populações indígenas ainda existentes na região devem ser mais carinhosamente olhadas pelo poder público, sabido que o Serviço de Proteção aos Índios, apesar de sua avultada folha de serviços depois de anos sem conta de dedicação e trabalho construtivo, não dispõe dos elementos materiais indispensáveis para a execução de toda a tarefa que lhe cabe.

Ajudar tecnicamente os aldeamentos de índios um pouco por toda a parte disseminados, ganhar para a civilização outros contingentes de selvícolas realizando obra de patriotismo e de humanidade, não pode deixar de atrair, pela significação moral e econômica do empreendimento, os planejadores da Valorização.

Não tem feito o Brasil o que estava ao seu alcance, sobretudo o que era de sua obrigação, no trabalho de civilizar os seus índios. Hoje sabe-se com tristeza e não sem remorso que as tribos dispersas na bacia amazônica lutam com tôda sorte de adversidades refugiados cada vez mais dentro da selva algumas delas, outras ainda em estado de franca hostilidade aos brancos como represália legitima à guerra impiedosa que sofrem.

O que é mais doloroso, porem, é não se terem facultado aos índios contactos pela civilização, aldeados sob proteção do poder público ou não, melhores oportunidades de trabalho, de bem estar e de educação.

Com justeza se refere ao problema o documento apresentado à SPVEA pelos dirigentes do Serviço de Proteção aos Índios chamando ademais, a atenção da Comissão de Planejamento para o fato de que os selvicolas das fronteiras virem mantendo intercambio mais ativo com os povos visinhos.

Há, portanto, no assunto aspectos diversos, desde o de defesa nacional até o econômico e social, para não aludir aos aspectos moral e até histórico, todos merecendo atenção especial da Valorização.

Outros paises americanos souberam melhor aproveitar para a vida nacional os seus contingentes indios. Para nós é esta a oportunidade de realizar com mais objetividade um programa de integração do índio na comunidade brasileira. Os aldeamentos existentes precisam 
ser dotados de recursos técnicos, educativos e assistenciais, que possibilitem aos indios um labor profícuo, melhores condições de existência e maior proveito nos benefícios da civilização. Já se fez alguma cousa neste sentido. Mas é preciso ampliar o raio de ação civilizadora.

Parece-nos que a efetivação de medidas tendentes a criar condições de vida laboriosa, sadia e feliz às aldeia de índios já trazidas à civilização, poderá concorrer fortemente pelo exemplo e estimulo e que as tribos, mais arredias se aproximem do progresso civilizante e sejam defendidas contra a doença, a perseguição impiedosa, míseras condições dos mais desprotegidos habitantes das selvas.

Um programa amplo, nesse sentido, é mais do que um objetivo de valorização econômica da Amazônia: é também dever de patriotismo e obrigação moral de todos nós para com os remanescentes de um dos grupos que entraram para a miscigenação do povo brasileiro.

Fonte: JORNALALTO MADEIRA. O Problema do Índio. Porto Velho, 16.03.1954. Ano XXXVI. n. 4505, p. 1. Nota: Eventuais incorreções gramaticais do original foram mantidas.

\section{Anexo 2: Quadros}

\section{Quadro 2: Indígenas como vítimas}

\begin{tabular}{|l|l|}
\hline $\begin{array}{l}\text { JORNALALTO MADEIRA. Ameaçada } \\
\text { de perecimento a raça indígena do Bra- } \\
\text { sil. Porto Velho, 19.12.1950. Ano XXXIII. } \\
\text { n. 3665, p. 1. }\end{array}$ & $\begin{array}{l}\text { A “raça indígena” é } \\
\text { percebida como ameaçada. }\end{array}$ \\
\hline JORNAL O IMPARCIAL. 27.01.1952. & $\begin{array}{l}\text { Em Ouro Preto, um } \\
\text { massacre cometido por um } \\
\text { seringalista foi relatado } \\
\text { pelo indigenista Francisco } \\
\text { Meireles, então chefe do } \\
\text { SPI. }\end{array}$ \\
\hline $\begin{array}{l}\text { JORNAL ALTO MADEIRA. Conflitos } \\
\text { sangrentos entre índios e os invasores } \\
\text { de suas terras. Porto Velho, 1953a. Ano } \\
\text { XXXVI, n. 4.280, p. 4. }\end{array}$ & $\begin{array}{l}\text { Onão índio é descrito como } \\
\text { "invasor” das terras indíge- } \\
\text { nas. }\end{array}$ \\
\hline
\end{tabular}

Organizado por Vinicius Valentin Raduan Miguel. 
Quadro 3: Indígenas como agressores

\begin{tabular}{|c|c|}
\hline $\begin{array}{l}\text { JORNAL ALTO MADEIRA. Voltaram } \\
\text { os índios a atacar. Porto Velho, } \\
\text { 30.12.1950. Ano XXXIII, n. 3671, p. } 1 \text {. }\end{array}$ & $\begin{array}{l}\text { “Novo apêlo da } \\
\text { Associação Comercial de } \\
\text { Altamira - Serão forçados } \\
\text { os seringueiros a abando- } \\
\text { nar os trabalhos". }\end{array}$ \\
\hline $\begin{array}{l}\text { JORNAL ALTO MADEIRA. } \\
\text { Seringueiros Escapam do Massacre } \\
\text { dos Índios no Município de Altamira. } \\
\text { Porto Velho, 31.12.1950. Ano XXXIII, n. } \\
\text { 3672, p. 1. }\end{array}$ & $\begin{array}{l}\text { Indígenas atacam } \\
\text { seringueiros no mesmo } \\
\text { município (Altamira-PA) } \\
\text { que já havia sido palco de } \\
\text { outras investidas. }\end{array}$ \\
\hline $\begin{array}{l}\text { JORNAL ALTO MADEIRA. Quatromil } \\
\text { xavantes preparam a vingança. Porto } \\
\text { Velho, 1953b. Ano XXXVI, n. 4398, p. } 4 .\end{array}$ & $\begin{array}{l}\text { Chacina de } \mathrm{S} \text {. Felix, onde } \\
\text { vinte índios foram } \\
\text { “ m a s s a c r a d o s } \\
\text { covardemente” e que, ago- } \\
\text { ra, preparavam a retaliação. }\end{array}$ \\
\hline
\end{tabular}

Organizado por Vinicius Valentin Raduan Miguel. 


\section{Quadro 4: Sobre o Estado e suas agências (SPI)}

\begin{tabular}{|l|l|}
\hline $\begin{array}{l}\text { JORNAL ALTO MADEIRA. Medidas } \\
\text { deverão ser tomadas. Porto Velho, 1951. } \\
\text { Ano XXXIII, n. 3724, p. 3. }\end{array}$ & $\begin{array}{l}\text { Os índios “estão pertur- } \\
\text { bando o trabalho em toda a } \\
\text { região" e assevera que “o } \\
\text { caso que de tão perto me- } \\
\text { rece esforços dos } \\
\text { responsáveis pela } \\
\text { produção amazônica”. } \\
\text { BCA, Ministério da Agricul- } \\
\text { tura e SPI. }\end{array}$ \\
\hline $\begin{array}{l}\text { JORNAL O IMPACIAL. 27 de janeiro } \\
\text { de 1952. }\end{array}$ & $\begin{array}{l}\text { Em Ouro Preto, um } \\
\text { massacre cometido por um } \\
\text { seringalista foi relatado } \\
\text { pelo indigenista Francisco } \\
\text { Meireles, então chefe do } \\
\text { SPI. }\end{array}$ \\
\hline $\begin{array}{l}\text { JORNAL ALTO MADEIRA. SPI, } \\
\text { serviço de proteção ao índio, avança } \\
\text { progressivamente. Porto Velho, 1955a. } \\
\text { Ano XXXVII. n. 4764. }\end{array}$ & $\begin{array}{l}\text { Demanda à SPVEA e ao SPI } \\
\text { para que “integrem” o } \\
\text { indio. }\end{array}$ \\
\hline $\begin{array}{l}\text { JORNALALTO MADEIRA. O Proble- } \\
\text { ma do Índio. Porto Velho, 1954b. Ano } \\
\text { XXXVI. n. 4505, p. 1. }\end{array}$ & $\begin{array}{l}\text { Relata a expansão do } \\
\text { serviço público voltado às } \\
\text { populações indígenas. }\end{array}$ \\
\hline $\begin{array}{l}\text { JORNAL ALTO MADEIRA.Em } \\
\text { dificuldades o S.P.I. regional de aten- } \\
\text { der pesados encargos que lhe são } \\
\text { afetados. Porto Velho, 1957b. Ano XL. } \\
\text { n. 5, p. 1. }\end{array}$ & $\begin{array}{l}\text { Incapacidade de atuação } \\
\text { governamental decorrente } \\
\text { da escassez orçamentária. }\end{array}$ \\
\hline
\end{tabular}

Organizado por Vinicius Valentin Raduan Miguel. 